\title{
Crispaciones hispánicas \\ (Reflexiones en torno a la terapia antinacionalista de Aurelio Arteta)
}

\author{
C. ULISES MOULINES \\ Universidad de Múnich
}

RESUMEN. Ésta es una respuesta a la crítica que Aurelio Arteta hace en su artículo «Un nacionalista en apuros» a mi ensayo «Manifiesto nacionalista», ambos aparecidos en esta misma revista. Respondo detalladamente a las objeciones presentadas por Arteta e identifico la posición del autor como la de un «contranacionalista» (en la acepción definida en mi ensayo): Arteta tiene que admitir la realidad empírica de las naciones (como entidades diferentes de los Estados) y, por tanto, su rechazo del nacionalismo sólo puede estar fundado en un rechazo del valor positivo de la diversidad cultural (que contiene la diversidad nacional). Arguyo, en contra de Arteta, que el pluralismo cultural, y en particular el nacionalismo, ni es incompatible con un espíritu democrático, ni conlleva relativismo alguno. En la parte final de mi artículo hago unas breves observaciones sobre las raíces del nacionalismo en el seno del Estado español.

En su artículo «Un nacionalista en apuros (El inconsistente separatismo de Ulises Moulines)», publicado en Isegoría (núm. 26, 2002, pp. 219-237), el Profesor Aurelio Arteta arremete en contra de las tesis que defendí, en las páginas de esta misma revista (núm. 24, 2001), en mi «Manifiesto nacionalista» (abreviado en lo sucesivo como $M N$ ). El propósito explícito de Arteta es mostrar las incongruencias de las que, en su opinión, está plagada mi defensa del nacionalismo en $M N \mathrm{y}$, de
ABSTRACT. This is a reply to the criticisms made by Aurelio Arteta in his article «Un nacionalista en apuros» to my essay «Manifiesto nacionalista», both published in this same journal. I answer in detail to the objections laid out by Arteta and I identify this author's position as a kind of «counternationalism» (in the sense defined in my essay): Arteta has to acknowledge the empirical reality of nations (as entities different from States) and, consequently, his rejection of nationalism may only be founded on his rejection of the positive value of cultural diversity (which includes national diversity). Against Arteta, I argue that cultural pluralism, and in particular nationalism is not incompatible with a democratic spirit, nor does it imply any sort of relativism. In the final part of my article I make some brief remarks on the roots of nationalism within the Spanish State.

paso, en un nivel más general, argüir que el nacionalismo es una posición esencialmente perversa.

Independientemente de las deficiencias de las que pueda adolecer mi argumentación y del valor que puedan tener las críticas de Arteta, lo que sorprende es la extrema virulencia de su texto. Abundan en él las alusiones ofensivas al autor de $M N$, a quien se refiere en varias ocasiones con expresiones del tipo «nuestro hombre» y otras de análogo cariz despectivo 
(pp. 220 y passim), califica mis tesis de «disparatadas» (p. 219) e «indignas de un ciudadano dotado de alguna conciencia crítica» (pp. 219-220), atribuye a mi argumentación «supuestos inmorales» (p. 224), para acabar acusándome de «deshonestidad intelectual» (p. 235) ${ }^{1}$.

Alguien podría pensar que el estilo de la crítica de Arteta no tiene mayor significación que la de cierta idiosincrasia personal o nacional. Y probablemente haya algo de eso: este texto nos confirma una vez más que en España sigue siendo difícil superar esa táctica discursiva, según la cual una crítica aparece tanto más convincente cuanto mayor sea la vehemencia con que se descalifique moral e intelectualmente al contrincante, ese mal endémico de los debates político-ideológicos en España, no sólo en las Cortes o en periodicuchos, sino incluso en foros intelectuales. Ahora bien, si sólo fuera eso, podríamos correr un tupido velo sobre este aspecto lamentable, pero superficial, del artículo de Arteta y pasar sin más a cuestiones más sustanciales. Sin embargo, creo que hay algo más de fondo en el ropaje estilístico con que este autor envuelve sus críticas a mi nacionalismo, algo que merece una seria consideración.

Es indudable que el texto de Arteta está inspirado, de cabo a rabo, por el odio y la crispación. De parte de un autor a quien apenas conozco personalmente $\mathrm{y}$ con quien no he tenido ningún contacto académico, cabe preguntarse por el origen de esa crispación. Creo que la clave del enigma la encontramos en los últimos párrafos de su artículo. Arteta nos advierte que quiere culminar su diatriba contra el autor de $M N$ con algo que él mismo califica de «argumento ad hominem», y aunque es sabido que tal tipo de argumentos tienen muy escasa fuerza probatoria, no puede reprimir el deseo de presentarlo. En efecto, nos relata que, como profesor de la Universidad del País Vasco adversario del nacionalismo vasco, se siente acosado por
ETA y sus simpatizantes, y que, por añadidura, algunos de sus colegas universitarios, nacionalistas vascos, han acogido favorablemente mi ensayo; de lo cual infiere mi «complicidad» (es su término y sus cursivas) con quienes lo acosan. La última frase de su escrito consiste en invitarme a que yo tome posición respecto al acoso que él sufre.

Debo confesar que tuve que releer varias veces el pasaje en cuestión para cerciorarme de que estaba yo entendiendo bien. Pues sí: a pesar de que la inferencia está construida de una manera discursivamente alambicada, una lectura atenta no permite otra interpretación de su sentido: Moulines defiende tesis nacionalistas, luego Moulines es cómplice de ETA. Espero que se me crea si digo que me quedé completamente pasmado ante la lectura de tal inferencia; y espero que haya todavía algún lector en la España actual que se quede igual de atónito que yo (que los habrá fuera de España, de eso afortunadamente no me cabe ninguna duda).

Quiero creer que la desorbitada acusación de Arteta en contra mía sea no más que un lapsus irreflexivo, causado por un estado de crispación, producto a su vez de la tensión que él vive personalmente en el País Vasco (y que, ça va de soi, lamento sinceramente). Ese estado anímico le conduce a asumir, sin mayor fundamento, lo que creo que es el principio implícito subyacente a su crítica de $M N$, un principio que puede expresarse en la doble ecuación:

Nacionalismo $=$ Nacionalismo vasco $=$ $=E T A$

Asumido este «principio guía», está claro que quien escribe un «Manifiesto» en favor del nacionalismo también está escribiendo un manifiesto en favor de ETA, y por tanto un manifiesto en favor de quienes ponen en peligro la seguridad del Profesor Arteta. He aquí las profundi- 
dades abismales del nivel en el que ha caído la discusión en torno a la problemática del nacionalismo en España. De parte de algún oscuro diputado del PP o del PSOE, la doble ecuación de marras, aunque lamentable, quizás no debería sorprendernos mayormente, dadas ciertas tradiciones carpetovetónicas de algunos políticos españoles; proveniente de un profesor universitario, causa escalofríos...

Espero que cualquier lector de esta réplica (incluido el propio Arteta) me conceda mi negativa rotunda a tan siquiera considerar para la discusión el «principioguía» mencionado. Está claro que, de hacerlo, quedaría cortada de cuajo cualquier posibilidad de debate mínimamente racional. Si toda discusión general sobre el nacionalismo ha de desembocar, en definitiva, en la cuestión de si alguien está a favor o en contra de ETA, entonces podemos ahorrarnos proseguir la discusión. Por ello, en las páginas que siguen me limitaré a responder al Profesor Arteta dejando fuera del horizonte tanto esa doble ecuación como los vituperios que pululan en su texto. Trataré de filtrar los argumentos más sustanciales y generales que ofrece en contra de mi posición. Esta tarea, por cierto, no es nada fácil, dado el carácter poco estructurado de su argumentación, los saltos repentinos de un punto a otro sin aparente ilación y, last but not least, el notable descuido con que ha leído lo que realmente aparece en mi texto ${ }^{2}$. Pero, en fin, veamos qué se puede hacer con la argumentación artetiana. Trataré de seguir sus puntos lo más fielmente posible.

Lo primero que me reprocha Arteta es que mi ensayo trata del nacionalismo sin mencionar una sola vez lo que ocurre en el Estado español, y en particular en el País Vasco, y ello a pesar de ser yo mismo español (p. 220). Arteta atribuye ese silencio a mi cobardía (no queda claro si ante ETA o ante el Juez Baltasar Garzón). Dudo en tomar este reproche como una objeción en serio, a menos que alguien crea que como principio metodológico general vale que, si un autor ciudadano del Estado $X$ trata en términos filosóficos de la cuestión del nacionalismo, lo tiene que hacer aplicando sus ideas explícitamente a los problemas del Estado $X$ (un ciudadano británico sólo debe tratar filosóficamente del nacionalismo si lo aplica al caso irlandés, un ciudadano francés si lo aplica al caso corso, y así sucesivamente). No veo ninguna razón para aceptar tal metodología y tales limitaciones, y menos en un contexto filosófico. Ella sería, en efecto, una forma extrema de meta-nacionalismo... Por lo demás, es cierto que soy un ciudadano español en el sentido de que soy portador de un pasaporte emitido por el Estado español; pero también soy ciudadano venezolano, y tampoco hay en mi ensayo ninguna mención de Venezuela (aunque allí también existe un movimiento nacionalista muy fuerte). Este otro silencio de mi parte no le molesta a Arteta, ya sea porque ignora mi doble ciudadanía, o bien porque el nacionalismo venezolano goza del soporte oficial del Estado y ése es el tipo de nacionalismo que no le causa ningún problema a mi crítico.

La razón principal por la que en $M N$ no hice ninguna mención explícita de España estriba sencillamente en que nada estaba más lejos de mi intención que publicar un artículo sobre la situación política interna del Estado español. Mi interés no fue la de defender la causa del nacionalismo en este o aquel país, sino solamente la de analizar en términos ontoepistemológicos generales el concepto de nación, argumentar en favor de la realidad empírica de su referente y abogar en favor del valor positivo de ese referente. Y si di algunos ejemplos de situaciones concretas en otros países fuera de España, fue porque los consideré particularmente paradigmáticos para ilustrar algún punto que me interesaba y porque, precisamente por su carácter «neutral» para un lector español, podían ser examinados por éste con cierta serenidad. Por lo demás, imagino los aspa- 
vientos de lectores españoles (probablemente del propio Arteta), si yo me hubiera arriesgado a aplicar en detalle mis tesis al caso español: «!Qué cara más dura tiene este tío!» - habrían exclamado, quizás con razón-, «lleva más de treinta años sin vivir aquí, ni siquiera es oriundo de España, y se atreve a darnos lecciones sobre lo que ocurre con los nacionalismos en nuestro país, sentado en la apacible cercanía del Englischer Garten muniqués, a dos mil kilómetros de distancia...».

De todos modos, para que Arteta se convenza de que no fue «cobardía» lo que me impidió referirme al caso español en $M N$, y dado que sospecho que, en el fondo, éste es el único caso que realmente le interesa cuando se discute sobre el nacionalismo, en un apéndice a esta réplica trataré de satisfacer su curiosidad y haré algunas observaciones sobre mi interpretación de la situación en España, si bien con el caveat explícito y enfático de que son las observaciones de alguien que hace mucho que no vive la cotidianidad de la política española, ni se dedica profesionalmente al análisis politológico del Estado español. Pero antes veamos cuáles son las objeciones de Arteta a mis tesis generales.

A este fin, quizás convenga recordar brevemente (para el lector que no haya leído $M N$ o ya no lo tenga presente) la «esencia» de mis tesis: 1) etnias y naciones son entidades con una existencia real (tesis ontológica); 2) no parece que exista un criterio fenomenológico unívoco para identificarlas, por lo que no conviene estudiarlas como si fueran entidades fenoménicas, sino más bien como entidades teóricas, análogas a entidades del mismo tipo en otras disciplinas de las ciencias naturales o sociales, que permiten explicar los fenómenos sin por ello identificarse con los mismos (tesis epistemo-metodológica); 3 ) es bueno un programa político que fomente la preservación y el desarrollo de las múltiples naciones que alberga el planeta. Este programa político es la esencia del nacionalismo. El nacionalismo es, en el ámbito de las entidades político-culturales, lo que el ecologismo en el ámbito de las entidades naturales. Las tesis 1 y 2 son claramente de exclusivo carácter ontoepistémico (o, si se quiere, teórico-descriptivo), la tesis 3 es de índole normativa o axiológica, y más particularmente éticopolítica. Está igualmente claro que de 1 y 2 no puede inferirse sin más $3 .^{\mathrm{a}}$, lo cual sería un caso patente de la famosa «falacia naturalista». Así lo señalo varias veces en $M N$, y por ello el reproche que me hace Arteta (p. 226) de cometer dicha falacia no puede ser (en la interpretación más benevolente) más que el producto de una lectura negligente de mi texto. 1 y 2 constituyen un fundamento para 3 en el siguiente sentido: si añadimos a las premisas teórico-descriptivas 1 y 2 una premisa axiológica general (lo que en $M N$ llamo «principio del valor intrínseco de la pluralidad del ser»), entonces sí está justificado inferir (ceteris paribus) 3. En ello no radica ninguna falacia, ni «naturalista» ni de otro tipo. Tanto en la vida cotidiana como en las ciencias aplicadas hacemos constantemente tales inferencias: de la premisa teórico-descriptiva «El virus del SIDA existe realmente aunque es difícil de detectar», más la premisa axiológica «Los virus infecciosos son nocivos», estamos justificados en inferir la consecuencia normativa «Hay que desarrollar un programa para combatir el virus del SIDA». Exactamente la misma estructura lógica general tiene mi argumentación pronacionalista, con la salvedad de que, a diferencia del caso del SIDA, aquí la conclusión normativa no es de carácter negativo, sino positivo.

El antinacionalista tiene dos opciones generales para contrarrestar mi argumentación: negar al menos una de sus premisas teórico-descriptivas (normalmente será la ontológica) o bien su premisa axiológica. Por ello distinguí en $M N$ dos formas posibles de antinacionalismo: el negacionismo y el contranacionalismo. El segundo con- 
siste justamente en comparar el caso de las naciones con el del SIDA: las naciones existen (aceptación de la premisa ontológica) pero son tan nocivas como un virus infeccioso (inversión de la premisa axiológica); por ello hay que desarrollar un programa político que las erradique, o al menos las reduzca a su mínima expresión. El negacionista, en cambio, ni siquiera admite las premisas teórico-descriptivas de mi argumento, en particular la ontológica $^{3}$. Al negacionista, el principio axiológico general le tiene sin cuidado: según él, en ningún caso puede inferirse la bondad del programa nacionalista. En efecto, si las naciones no existen, está claro que no tiene ni siquiera sentido preguntarse si es bueno o malo desarrollar un programa para su preservación y desarrollo. Sería como preguntarse si es bueno o malo preservar los centauros.

Me parece evidente que negacionismo y contranacionalismo son opciones radicalmente diferentes en una argumentación en contra del nacionalismo. Y el antinacionalista debería decirnos claramente si opta por una u otra; de lo contrario, nunca sabremos exactamente cuál es su estrategia de argumentación y la discusión se tornará confusa. ( $\mathrm{Si}$ queremos desengañar a alguien que espera de los marcianos la salvación de la Humanidad, tenemos que decidirnos por, o bien convencerlo de que los marcianos no existen, o bien persuadirlo de que existen, pero son seres muy peligrosos; lo que no podemos hacer es transitar por ambas vías argumentativas a la vez.) Lo curioso es que, en el debate en torno al nacionalismo, los antinacionalistas, no siempre, pero sí con sorprendente frecuencia, se muestran insensibles a esta evidente diferencia y mezclan alegremente argumentos negacionistas y contranacionalistas. El artículo de Arteta no es una excepción a esta regla. Por un lado, afirma simpatizar con el negacionismo (p. 221), ironiza sobre el carácter «difuso» (como yo mismo explico) de los criterios de iden- tidad de etnias y naciones, que para él son síntomas de su carácter ilusorio (pp. 222 y 223), hace notar que la noción de etnia fue «un invento de la antropología colonial inglesa» (p. 222) - lo cual, dicho sea de paso, no implica nada acerca de la realidad o irrealidad del referente de esa nocióny alaba a Max Weber por «arrojar por la borda los conceptos de etnia y nación», así como a Gellner por «negar pura y simplemente la existencia de naciones» (p. 237, n. 6). Estos pasajes y otros parecidos parecen indicar, fuera de toda duda razonable, que Arteta es un negacionista en el sentido preciso aquí expuesto. Y, sin embargo, otros tantos pasajes indican justamente lo contrario. Para empezar, inmediatamente después de su declaración pronegacionista, Arteta nos advierte que ese negacionismo podría, «sin incurrir en absurdo alguno, afirmar la existencia de una nación y a la vez tildar ese sentimiento de amor a la patria como producto de una ilusión o quizás incluso de una alucinación. Exista o no nación en algún sentido verificable, por lo pronto, lo ilusorio suele ser la historia que el patriota se inventa»(p. 221). Naturalmente, cada uno es libre de definir sus términos como le convenga, y Arteta podría haber definido «negacionismo» de otra manera distinta a la mía (por ejemplo, como la negación de historias ilusorias sobre una nación realmente existente). Pero lo enojoso es que aquí está discutiendo un concepto que yo introduje como terminus technicus en mi ensayo con una definición totalmente precisa: negacionis$\mathrm{mo}=$ negación de la realidad de las naciones. Arteta está discutiendo explícitamente mi concepto, y entonces no vale dar de él de repente otra acepción que no tiene nada que ver con el uso propuesto por el autor a quien se critica. Lo que está en cuestión es la existencia real de las naciones, no la de si la gente tiende a asociar con su nación quién sabe qué heroicas pero vanas leyendas. Podemos atribuir a nuestros padres o a nuestros hijos quién sabe qué dechados 
de virtudes sobrehumanas y luego alguien nos puede hacer notar que todo eso es una ilusión, que en el fondo se trata de pobres diablos como cualquier hijo de vecino; ello no implica que la existencia de esos padres o hijos sea una ilusión. Creer en la realidad de la nación $N$, aunque sea nuestra propia nación, no significa creer que de $N$ sólo pueden relatarse historias maravillosas. Incluso podemos amar profundamente a $N$ y ser muy críticos con muchos de sus aspectos idiosincrásicos. (Lo mismo vale, por supuesto, con todo lo que se ama, sean personas, gatos o cualquier otra cosa.)

Así pues, el negacionismo del que habla Arteta y con el que parece simpatizar en varios pasajes de su artículo no tiene nada que ver con el negacionismo que yo discuto en $M N$. Y seguimos sin saber si Arteta es negacionista en este sentido o no. Pero hay más. Otros pasajes de su escrito apuntan hacia una sólida creencia en la realidad de las naciones, sean éstas entidades dañinas o no. Así, en la página 231 leemos: «En lo que atañe a las naciones igual que a los puntos de vista, la pluralidad de unas y otros será inevitable, pero no por fuerza buena.» No veo otra manera de interpretar este enunciado como la aceptación de la existencia de una pluralidad de naciones, aunque ello no sea necesariamente benéfico (lo cual no es ahora lo que está en discusión). Previamente, hablando de España, califica este país como «Estado multinacional» (p. 226), lo cual, bajo cualquier acepción razonable del calificativo «multinacional», significa que el Estado español abarca varias naciones (las cuales, por tanto, existen y no son meras ficciones). Y, para terminar, Arteta cita, asumiéndolos, ciertos datos estadísticos recientes sobre la relación entre Estado y nación: «Sólo un 17 por 100 de los Estados se ajustaban [en 1989] al ideal de la correspondencia biunívoca entre nación y Estado» (p. 236). Este dato estadístico sólo tiene sentido si: $a$ ) asumimos que los conceptos de Estado y nación no son coextensivos (lo cual, por cierto, es una de las tesis principales de $M N)$, y $b$ ) el concepto de nación se aplica a entidades realmente existentes (otra tesis principal de $M N$ ). Estas citas del propio Arteta carecerían por completo de sentido si él efectivamente quisiera, con Weber, «echar por la borda los conceptos de etnia y nación» (p. 237) o, con Gellner, «negar pura y simplemente la existencia de naciones» (ibid.). En vista de estas citas, no resisto a la tentación de preguntarle a mi crítico: ¿En qué quedamos? Etnias y naciones, ¿existen realmente o no?

Si tratamos de hacer las disquisiciones de Arteta más consistentes de lo que el texto mismo, tomado literalmente, nos permite, creo que la interpretación más benevolente sería la de que su autor admite la existencia real de las naciones, aunque son entidades que le caen antipáticas, debido a su supuesto carácter perjudicial para la Humanidad. Estamos en la analogía con el virus del SIDA. Esto, por lo menos, es coherente; pues si algo le cae antipático a alguien, lo primero que ese alguien tiene que hacer es aceptar la existencia de ese algo. Constatemos: Arteta acepta la existencia de las naciones pero considera esa existencia una desgracia. Ésta es exactamente la posición que en $M N$ definí como «contranacionalismo». Arteta no es un negacionista (como él mismo se atribuye), sino un contranacionalista. En lo sucesivo, mis respuestas a sus objeciones se basarán en el supuesto de que se trata de las objeciones de un contranacionalista. Veamos entonces qué argumentos trae nuestro crítico a colación en favor de la tesis de que las naciones, aun existiendo, o precisamente por ello, son perjudiciales y de que por tanto el nacionalismo, como programa político de preservación y fomento de las naciones, debe ser radicalmente combatido.

La objeción más fuerte, y de hecho la única que elabora ampliamente, la encon- 
tramos ya en las primeras páginas de su artículo, y consiste en sostener que ese programa de preservación y fomento de las naciones (que es a lo que yo explícitamente denomino «nacionalismo») representa una forma de demencia colectiva: «ciertamente, el crítico del nacionalismo lo mira como un "grave desorden psíquico" y no habrá ciudadano digno de tal nombre que se engañe acerca de sus peligros manifiestos y no procure reprimirlo o superarlo» (p. 221). Y un poco más adelante añade: «nada tiene de extraño que el negacionista (es decir, el propio Arteta; es decir, un contranacionalista) - si es un ciudadano demócrata y por la cuenta que le trae - tenga por deber moral ( $\mathrm{y}$, en primer término, político) curar (cursivas de Arteta) a los pacientes de tal ilusión o reprimirla» (ibid.).

Si bien Arteta no nos revela cuáles son los criterios psiquiátricos en los que se basa para diagnosticar que los nacionalistas son pacientes de un grave desorden psíquico, hay que reconocer que, aunque sea al modo de una afirmación dogmática, pocas tesis en su artículo son tan meridianamente claras como ésta. He aquí las líneas fundamentales del programa antinacionalista que él propone. En primer lugar, todo «ciudadano digno de tal nombre» tendrá por «deber moral» reprimir a los nacionalistas. (Dada la formulación general que da Arteta a su programa, supongo que los «ciudadanos dignos de tal nombre» deben reprimir a los nacionalistas en cualquier parte del mundo en que se encuentren; pero en particular, naturalmente, a los nacionalistas que se encuentren dentro de las fronteras del Estado español.) Quien no esté dispuesto a asumir este «deber moral» de represión (para no hablar ya de los propios afectados, los nacionalistas) no es «ciudadano digno de tal nombre», es alguien que falta a su deber cívico (y por tanto habrá que sancionarlo, aunque Arteta no dice cómo). En segundo lugar, no obstante, Arteta es tan humanitario con los nacionalistas que la vía de represión en la que piensa parece ser de orden psicoterapéutico - no aconseja las torturas ni los fusilamientos-. Es decir, a los nacionalistas hay que «curarlos» de su ilusión, precisamente puesto que ya hemos visto que se trata de un grave desorden psíquico (y además muy peligroso para el bienestar de la colectividad). Ahora bien, advierte Arteta en su infinita clemencia, esta terapia hay que aplicarla «a través de los cauces de un Estado de Derecho» (p. 221). La cuestión a la que no da respuesta Arteta es qué pasa si los pacientes de tan grave enfermedad no quieren «dejarse curar». Podemos dar la respuesta por él, dadas las premisas de su análisis. En efecto, ¿qué hace todo Estado de Derecho con dementes peligrosos que no quieren someterse voluntariamente a una terapia? Pues bien, los encierra por la fuerza en un manicomio. (Aquí se presenta un pequeño problema técnico: dados los millones de nacionalistas que viven en España, como en muchos otros países, estos manicomios en los que habría que encerrarlos para tratarlos adecuadamente deberían ser necesariamente de un género muy especial por sus dimensiones, algo que podría recordar Auschwitz, por ejemplo.)

Por cierto que la propuesta artetiana ni siquiera tiene el sello de la originalidad. Todos recordamos que en la última fase del sovietismo (de Bréjnev hasta Andropov) a los estrategas del Kremlin se les ocurrió una manera más «suave» de tratar a los contrincantes político-ideológicos que la clásica del tiro en la nuca o los trabajos forzados en el GULAG: previo despojo de sus derechos ciudadanos, se les encerraba en asilos mentales, donde se les «curaba» de sus «ilusiones» y «alucinaciones». A la postre, ello no sirvió de gran cosa; pero quizás Arteta crea que él y el Estado español serán más eficaces que los soviéticos, o que tendrán mejor fortuna.

Llegados a este punto, el autor de estas líneas tiene dos opciones. O tomar literal- 
mente lo que Arteta dice en los pasajes citados (y en algún otro inciso de parecido calibre), en cuyo caso cualquier debate ulterior se vuelve imposible, o pasarlo por alto como uno más de sus exabruptos producto del fragor de la lucha y averiguar si en su ataque al nacionalismo hay otros puntos que pueden discutirse razonablemente. Ante esta disyuntiva, sigo el principio in dubio pro reo y escojo la segunda opción. ¿Qué otras objeciones tiene Arteta que hacer al nacionalismo, aparte de su caracterización como forma peligrosa de demencia que hay que «curar»?

Su objeción más general se refiere a la premisa axiológica de mi argumentación pronacionalista, o sea lo que en $M N$ aparece como el principio del Valor Intrínseco de la Pluralidad del Ser (o principio $V I P S)$ : «es algo bueno, que hay que preservar, o hasta fomentar en la medida de lo posible, el que haya muchas cosas de muy diversos tipos en el universo». Arteta no quiere aceptar este principio: «Enunciemos, pues, el principio opuesto, el del valor intrínseco de la unidad o armonía del ser» (p. 232, sus cursivas). Y en ello está claro que no comete ningún error lógico ni fáctico. Yo mismo señalo en $M N$ que VIPS es un principio muy básico de naturaleza ético-estética, que no puede fundamentarse en otros. O lo tomamos o lo dejamos. A quien, de entrada, tenga otra escala de valores (una escala en la que lo ideal sería que la realidad fuera lo más homogénea posible en todo el universo, siendo el caso perfecto el vacío absoluto) está claro que no lo podremos convencer con nuestro principio pluralista. Tampoco podremos convencer a quien de entrada prefiera vivir en la Luna que en la Tierra; la superficie de la Luna es ciertamente más armónica que la de la Tierra: no hay en ella la contraposición entre invierno y verano, entre mar y tierra, entre regiones desérticas y selváticas, entre millones de especies animales y vegetales, cada una defendiendo sus intereses, entre grandes ciudades y lugares deshabitados, entre catedrales y chozas, entre automovilistas y peatones... y por supuesto entre muy diversas naciones. La Luna es de una cuasi perfecta armonía. Parece que Arteta preferiría vivir en la Luna; yo prefiero vivir en la Tierra. No hay un criterio más fundamental para dirimir nuestro disenso preferencial. Lo único que cabría observar aún es que el principio monolítico y homogeneizador de Arteta choca de frente con un vasto movimiento, cada vez más divulgado en todos los países, organizaciones internacionales y también entre los ciudadanos comunes y corrientes: el ecologismo, es decir, la familia de programas que promueven la diversidad natural, y en particular la biodiversidad, o sea, la preservación de cuantas especies animales y vegetales sea posible, incluso y especialmente las que están amenazadas de extinción. El principio artetiano, por definición, no sólo es antinacionalista, también es antiecologista (pues el ecologismo no es otra cosa que el nacionalismo de las especies naturales, o si se prefiere al revés, el nacionalismo es el ecologismo de las naciones). No sé si Arteta es plenamente consciente de las consecuencias universales de su propio principio; pero ése es un asunto que él mismo debe dirimir.

Es posible que Arteta no prevea una aplicación tan universal de su principio. Aunque la formulación del mismo en la página 232 es ontológicamente irrestricta, unas páginas antes, cayendo en otra de las incongruencias que tanto me achaca, leemos: «Ignoro si es verdad necesaria que el universo sea ontológicamente más rico cuanto más diverso [...]. En lo que se refiere a nosotros, tal es nuestra semejanza básica que ya el mero subrayado de la diferencia se vuelve sospechoso» (p. 227). Quizás podríamos parafrasear el monolitismo de Arteta de la siguiente manera: «Me da absolutamente igual si hay que valorar positivamente un mundo con diversi- 
dad natural; en cualquier caso debemos estar en contra de valorar positivamente la diversidad cultural.» Es decir, el «principio del valor intrínseco de la unidad o armonía del ser», enunciado de manera irrestricta en la página 232, valdría en realidad sólo en su aplicación al ser cultural. Esta interpretación light de su principio viene avalada por los pasajes en los que ataca mi principio VIPS no por la contemplación general del Universo que propone, sino por sus consecuencias en el mundo de la cultura: «Aquel principio (o sea, VIPS) funda más bien la tesis capital del multiculturalismo y otros torpes relativismos de nuestros días: que las cosas (o conductas o culturas) no son valiosas por lo que como tales valgan, sino nada más porque son varias o distintas entre sí» (p. 228). Presenciamos aquí uno de tantos ejemplos de las amalgamas precipitadas que abundan en el texto de Arteta. ¿En qué se basa para identificar el multiculturalismo con el relativismo? Naturalmente podemos identificarlos por definición. Pero con eso no hacemos avanzar en nada la discusión. El multiculturalismo en el sentido defendido en $M N$, es decir, la valoración positiva de la diversidad de formas culturales, es lógica y axiológicamente independiente del relativismo como afirmación de que todo tiene el mismo valor. Que en principio sea bueno que se desarrollen diversas formas culturales no implica de ningún modo que todas las formas posibles tengan el mismo valor, ni que no pueda haber algunas de ellas dañinas para el conjunto del universo cultural. Estoy firmemente convencido de que la Pasión según San Mateo tiene mucho mayor valor que las canciones de Julio Iglesias; pero al mismo tiempo considero bueno que el universo musical no se restrinja a las obras de Bach, sino que también le deje su lugarcito a las cancioncillas de moda. Y en todo caso, creo que debemos respetar a quienes prefieren escuchar a Julio Iglesias en vez de a Bach, aunque no compartamos su escala de valo- res musicales. No hay en ello ninguna contradicción, ni lógica, ni axiológica. De hecho, en el ámbito cultural vale lo mismo que en el ámbito de la política: la Historia nos muestra que es mejor una sociedad en la que se admiten (e incluso se fomentan) diversos partidos políticos que otra en la que rige un solo partido (supongo que incluso Arteta estará de acuerdo con este principio de pluralismo político o «multipoliticismo»). Ello no implica ni connota que no podamos estar convencidos de que, en un momento dado, ciertos partidos son mejores para la marcha de la sociedad que otros; incluso es compatible con el pluralismo político el que estemos convencidos de que algunos partidos políticos (por ejemplo, los que promueven encerrar a sus contrincantes en campos de concentración o en asilos mentales) son definitivamente nefastos.

Me cuesta creer que Arteta sea realmente el antimulticulturalista, o sea, monoculturalista, que dice explícitamente ser. ¿Es cierto que prefiere una situación en la que todos los habitantes del planeta se vistan de la misma manera, gocen de la misma gastronomía, oigan la misma música, pinten en el mismo estilo, cuenten los mismos chistes, practiquen el mismo deporte... y hablen una sola y misma lengua (el inglés, por supuesto, pues no hay otro candidato verosímil a la vista)? Es difícil de imaginar; pero si es realmente así, no tengo nada más que replicarle, aparte de señalar que, para mi fortuna y para su desgracia, y al igual que en el caso del ecologismo, cada vez es más fuerte un movimiento planetario en favor de la diversidad cultural en todos los niveles: de parte de instituciones gubernamentales y no gubernamentales, de organizaciones regionales (como la Unión Europea) e internacionales, y nuevamente también de parte de ciudadanos comunes y corrientes. Este movimiento culminó en octubre de 2001 en la Declaración Universal de la UNESCO sobre la Diversidad Cultural. En el artícu- 
lo 1 de esta Declaración leemos que «la diversidad cultural es, para el género humano, tan necesaria como lo es la biodiversidad en el orden de los seres vivos. En este sentido, ella constituye el patrimonio común de la humanidad y debe ser reconocida y afirmada en beneficio de las generaciones presentes y de las generaciones futuras». Y el artículo 4 asienta: «La defensa de la diversidad cultural es un imperativo ético, inseparable del respeto a la dignidad humana.» Este texto ha sido suscrito por prácticamente todos los Estados del mundo, incluyendo el Estado español. Es más, en el momento en que escribo estas líneas, la Declaración Universal de la UNESCO va por buen camino de convertirse en lo que en Derecho internacional se conoce como una Convención, es decir, un instrumento jurídico de carácter obligatorio para todos los Estados que lo hayan suscrito (por ejemplo, el Estado español), $\mathrm{y}$, por transferencia, para todas las instituciones de los mismos. La Convención prevé obligar a los Estados explícitamente a promover la diversidad cultural en todas sus formas y en todos sus niveles, y en particular también a promover las lenguas minoritarias, incluso y especialmente las lenguas amenazadas de extinción. Así que si Arteta se manifiesta en contra de la diversidad cultural y en particular en favor de que no se haga nada por preservar, «verbigracia, una lengua prácticamente desaparecida o en trance de desaparición» (p. 228), se está oponiendo no sólo a la UNESCO y a la comunidad internacional, sino incluso al propio Estado español (al menos en sus declaraciones oficiales).

No deja de ser una ironía que mi crítico me reproche promover a la vez el multiculturalismo y el relativismo. Es cierto que soy un multiculturalista convencido; pero es igualmente cierto que soy un acendrado adversario del relativismo, al cual me propuse refutar sistemáticamente en un capítulo entero de Pluralidad y recursión (que Arteta probablemente no conoce, dicho sea en su descargo) ${ }^{4}$. En mi libro no traté de cuestiones ético-políticas, pero mi argumento de que el pluralismo epistémico más decidido es compatible con un igualmente decidido antirrelativismo es aplicable mutatis mutandis al ámbito político y a la tesis de que el multiculturalismo es compatible con un espíritu democrático universal. Lo cual, dicho sea de paso, no es una extravagancia de mi parte. Otros autores, que han tratado sistemáticamente de la relación entre multiculturalismo y democracia, ven perfectamente compatibles ambos términos; así Ferran Requejo, cuando escribe: «Obviamente, contextualizar los diferentes enfoques teóricos subrayando a la vez su pluralidad no implica la aceptación de un relativismo epistemológico o moral de naturaleza "post-moderna", sino que más bien cuestiona las pretensiones de "unicidad fundamental" de algunas teorías contemporáneas de la democracia» ${ }^{5}$.

En realidad, nuevamente tengo mis dudas acerca de si la cuestión de la diversidad cultural es la que realmente le preocupa a Arteta. Es posible que él no tenga verdaderos problemas con la diversidad de tradiciones musicales, culinarias, lúdicas, etc. La diversidad cultural quizás sólo le molesta en la medida en que ella pueda fundamentar (no por un razonamiento deductivo, pero sí por una inferencia analógica) la diversidad nacional. Es posible que haya que restringir aún más el alcance de su principio del «valor intrínseco de la unidad o armonía del ser», parafraseándolo así: «Me da absolutamente igual la diversidad natural, y puedo hasta tolerar que haya diversas manifestaciones culturales de tipo musical, gastronómico, etc. Pero lo que de ningún modo puedo admitir es la diversidad de naciones.» Esta interpretación parece plausible ante el colofón que añade inmediatamente a su principio del valor intrínseco de la unidad del ser: «procuremos enraizarlo como el apoyo más firme de la política nacional e interna- 
cional. Lo que hay que preservar y hasta fomentar en lo posible es la unidad en la diversidad» (p. 232).

Reconozco que, al leer estas frases, no pude evitar sentir un ligero escalofrío (otro más). Cuando alguien, en el ámbito político, enfatiza la unidad por encima de todo, no puedo dejar de pensar dónde está la Embajada más próxima para pedir asilo. Al leer el alegato de Arteta en favor de la unidad como «apoyo más firme de la política nacional e internacional», me vino automáticamente a la memoria la caracterización falangista de la nación hispánica como «unidad de destino en lo universal»; vi ante mis ojos el eslogan impreso en tantos documentos oficiales y monumentos «España una, grande, libre», y recordé el insoslayable inicio de los discursos soporíferos con que nos regalaba el Innominable regularmente: « ¿Españoles todos!». Seguramente estas asociaciones son injustas con Arteta (no sé nada de su curriculum político, aparte de que es un feroz adversario del nacionalismo vasco); pero son asociaciones biográficamente inevitables para alguien que ha tenido que soportar en Cataluña diez años de «unidad sagrada de España», en nombre de la cual se cometían toda clase de atropellos, y que ahora, más de treinta años después, tiene que leer la enfática declaración artetiana en pro de la unidad, en el contexto de un artículo en el que, al mismo tiempo, se califica al adversario político de demente y/o inmoral, y se aboga sin cortapisas por su represión. He aquí mi propio argumentum ad hominem, por si a Arteta le interesa. Pero como ya hemos dicho que tal tipo de argumentos son de dudosa fuerza probatoria, pasemos a otra cosa.

Una distinción que introduce Arteta en su ataque al nacionalismo estriba en la diferencia entre «nacionalismo político»y «nacionalismo étnico» (p. 232). Con el primero, Arteta se muestra benevolente (pp. 232-233), ante el segundo sólo cabe un rechazo frontal. Con lo cual, de repen- te, el antinacionalismo de Arteta deviene un poco aguado. Resulta ahora que no todo nacionalismo es intrínsecamente perverso: hay uno, el «político», que es bueno o por lo menos éticamente neutral; el malo es el «étnico». Ahora bien, el «nacionalismo político», con el que Arteta no tiene problemas, tiene que estar obviamente enraizado en una nación (de lo contrario no sería justamente un «nacionalismo»); de lo cual se desprende que las naciones no sólo existen, sino que además no siempre son tan malas como Arteta nos las quiere pintar. Por mi parte, no puedo atar cabos con esta distinción. Según la concepción que defiendo en $M N$ todo nacionalismo es a la vez político y étnico. Es político por cuanto consiste en un programa de acción política; y es étnico porque se basa justamente en una nación, que es una forma especial de etnia. (Todo esto está claramente expuesto en la parte final de $M N$.)

Pero quizás el «nacionalismo político» de Arteta es un misnomer para algo que no tiene nada que ver con el nacionalismo, sea éste bueno o malo. Parece que por «nacionalismo político» entiende él algo así como «republicanismo» o «ser buen ciudadano» del Estado en el que a uno le ha tocado vivir. No estoy seguro de esta interpretación (el texto de Arteta es en este punto particularmente confuso), pero poco después de su distinción entre nacionalismo político y étnico, leemos la siguiente declaración: «El enemigo genuino del nacionalismo (étnico) es el principio de ciudadanía, o sea, el principio democrático en su versión republicana» (p. 233). Esto puede leerse de dos maneras: o bien como una ulterior elaboración de lo que ya habíamos visto en páginas anteriores, o sea, que los nacionalistas son por naturaleza malos ciudadanos y por tanto hay que despojarlos de sus derechos de ciudadanía («curarlos», reprimirlos, etc.); o bien, de manera más inofensiva, como la contraposición entre nacionalismo, por un lado, y 
democratismo o «republicanismo» («nacionalismo político»), por otro. Pero ¿qué razón hay para esta contraposición? ¿De dónde viene la incompatibilidad entre amar la propia nación, tratar de preservar su propia lengua, tradiciones culturales, memoria histórica, etc., y ser un buen ciudadano, en el sentido de acatar las leyes y principios democráticos que rigen el Estado que alberga esa nación? Está muy bien ser «republicano». Pero ¿de qué República se trata? ¿De una «República universal»? Eso no existe, ni parece que vaya a existir pronto, a menos que se entienda por tal el Superimperio Anglosajón. Toda «República» actual, es decir, todo Estado más o menos democrático, abarca en su seno una $\mathrm{o}$ varias naciones concretas. $\mathrm{Y}$ parece un hecho empírico indudable que los ciudadanos de un Estado $E$, que pertenecen a la nación $N$, se sienten tanto mejor representados por $E$, y por tanto son mejores ciudadanos, cuanto mejor perciben que $N$ está bien acogida en $E$. (¿En qué sentido son peores demócratas ahora los ciudadanos eslovenos, después de que mandaron a volar el Estado hegemonista yugoslavo, que cuando tenían que lidiar constantemente con la prepotencia serbia? El sentido de las reglas democráticas está mucho más afianzado ahora en Eslovenia que hace veinte o treinta años y por eso justamente ese país ingresará pronto en la Unión Europea.)

Para remachar el clavo de su antinacionalismo, Arteta hace una afirmación que, en su infinita generalidad, es infinitamente injusta: «no hay etnia o nación que para afirmarse no se incline a negar a las vecinas» (p. 231). Ante una tesis tan descomunalmente apodíctica, para la que Arteta no ofrece la menor base estadística, no podemos sino sacudir la cabeza, y limitarnos a pensar en inmediatos contraejemplos. ¿Qué etnias o naciones vecinas están negando los eslovenos desde que disponen de un Estado nacional propio? ¿Qué etnias o naciones vecinas han negado o están negando los holandeses después de que en el siglo XVII se sacaron de encima el Estado hegemonista español? ¿O los costarricenses desde hace casi dos siglos? ¿O los germano-suizos desde hace tiempo inmemorial? ¿O los portugueses desde que disponen de un Estado democrático? Tan pronto como una nación se siente bien acogida en un Estado, sea éste un Estado uninacional o multinacional, por lo general deja de incordiar a los vecinos. Hay, por supuesto, lamentables excepciones a esta regla; pero aquí hablo de la tendencia general, que podría constatarse en otros muchos ejemplos, y que en cualquier caso refuta definitivamente el «axioma» artetiano. Sostiene Popper que basta un solo contraejemplo para refutar una teoría general. Aunque, siguiendo a Kuhn, no aceptemos la rigurosa metodología popperiana, la tesis artetiana de la innata tendencia agresiva de las naciones se enfrenta a tal cúmulo de «anomalías» empíricas, que hay que desecharla sin mayores miramientos. Por otro lado, incluso en aquellos casos en que una nación, que lucha por la constitución de un Estado que la represente bien, tiene que oponerse, a veces con las armas, a otra nación más poderosa, ello no significa que la primera quiera negar el derecho a la existencia de la segunda. Los chechenos no quieren negar el derecho a la existencia de los rusos: simplemente quieren que los dejen en paz para construir su propio Estado.

Otra afirmación intolerablemente injusta que suelta Arteta de pasada es la de que las reivindicaciones nacionalistas responden a resentimientos que, en el mejor de los casos, provienen de una posible injusticia cometida en un pasado remoto, pero sin ninguna vigencia en la actualidad: «Lo habitual, sin embargo, es que en los actuales [Estados] no subsista ya una conciencia étnica tan resentida y, aunque así fuera, toca preguntarse si está justificada una "acción afirmativa" o de "discriminación positiva" que pretendiera reparar un 
crimen remoto por otro probable crimen presente» (p. 226). Puedo comprender que a Arteta le afecte más que nada lo que pasa en el País Vasco; pero me cuesta imaginar que su horizonte político sea tan estrecho que no le haya llegado algún eco de lo que ha sucedido en otros lugares del mundo recientemente o lo que estaba sucediendo en el momento mismo en que escribía su texto. Le sugiero que las próximas vacaciones las vaya a pasar al Kosovo, a Chechenia, al Kurdistán turco, o si quiere más cerca, al Sahara Occidental o a la Kabylia argelina, y a su regreso nos convenza de que las terribles injusticias cometidas por un Estado hegemónico contra una nación minoritaria son cosa de un pasado remoto... Pero quizás a Arteta no le interesan en absoluto las cosas que están pasando actualmente en lugares tan «remotos»: cuando se trata de la cuestión del nacionalismo, a él sólo le importa lo que ocurre entre el Bidasoa y el Ebro. Le sugiero entonces que no vaya a pasar sus vacaciones en los susodichos lugares remotos, sino que se tome un par de horas para llegarse hasta Guernica, a no muchos kilómetros de su residencia. Allí podrá entrevistar sin duda a algunos sobrevivientes o familiares de víctimas del crimen de etnocidio cometido en 1937 (por causas estrictamente nacionales, y no de estrategia militar) por parte de los hegemonistas alemanes actuando por encargo de los hegemonistas españoles, por cierto, un acto por el que, si no me equivoco, el actual Estado español, jurídicamente el sucesor del Estado franquista, no ha pedido formal y explícitamente disculpas a la nación vasca (como han hecho otros Estados europeos en circunstancias semejantes). Esto también es una forma terrible de agravio y no precisamente ubicada en un pasado remoto ${ }^{6}$.

Una última observación estadística, antes de pasar a mi modesta toma de posición respecto al caso español. Ya hemos visto que, en la última página de su artículo,
Arteta aporta un dato estadístico del año 1989 proveniente de otros autores, según el cual «sólo un 17 por 100 de los Estados se ajustaban [en 1989] al ideal de la correspondencia biunívoca entre nación y Estado» (p. 236). Y a renglón seguido da a entender que la tendencia general es (o debería ser, no queda claro) hacia la desaparición de los Estados nacionales y la constitución de Estados multinacionales. Veamos qué ha ocurrido en el mundo desde la fecha indicada por Arteta. Averigüemos el número de Estados nacionales que se han constituido por secesión de Estados multinacionales previos (por las buenas, por las malas, por las semibuenas o por las semimalas) ${ }^{7} \mathrm{y}$ comparémoslo con el número de nuevos Estados multinacionales que se han constituido por la fusión de dos o más naciones en un solo Estado. He aquí la tabla:

Naciones que han constituido su propio Estado nacional por secesión de un Estado multinacional previo $^{8}$ :

- Estonia (por las semibuenas, secesión de la Unión Soviética).

- Letonia (por las semibuenas, secesión de la Unión Soviética).

- Lituania (por las semimalas, secesión de la Unión Soviética).

- Bielorrusia (por las semibuenas, secesión de la Unión Soviética).

- Ucrania (por las semibuenas, secesión de la Unión Soviética).

- Moldavia (por las semimalas, secesión de la Unión Soviética).

- Eslovaquia (por las buenas, secesión de Checoslovaquia).

- Eslovenia (por las semimalas, secesión de Yugoslavia).

- Croacia (por las malas, secesión de Yugoslavia).

- Macedonia (por las semibuenas, secesión de Yugoslavia).

- Kosovo (de facto, aunque no de iure, por las malas, secesión de Yugoslavia). 
- Georgia (por las semibuenas, secesión de la Unión Soviética).

- Armenia (por las semibuenas, secesión de la Unión Soviética).

- Azerbaidján (por las semibuenas, secesión de la Unión Soviética).

- Kazhakistán (por las semibuenas, secesión de la Unión Soviética).

- Turkmenistán (por las semibuenas, secesión de la Unión Soviética).

- Uzbekistán (por las semibuenas, secesión de la Unión Soviética).

- Tadjikistán (por las semibuenas, secesión de la Unión Soviética).

- Kirghistán (por las semibuenas, secesión de la Unión Soviética).

- Parte de Kurdistán (de facto, aunque no de iure, por las malas, secesión de Irak).

- Parte de Palestina (de facto, aunque no de iure, por las malas, secesión de Israel).

- Eelam (de facto, aunque no de iure, por las malas, secesión de Sri Lan$\mathrm{ka})$.

- Timor Oriental (por las malas, secesión de Indonesia)

- Eritrea (por las malas, secesión de Etiopía).

- Namibia (por las malas, secesión de la Unión Sudafricana).

\section{Total: 25 (veinticinco).}

(Si borramos de la lista las naciones que han conseguido la independencia sólo de facto, pero no de iure, nos quedamos de todos modos con 21 nuevos Estados nacionales reconocidos por la ONU).

Y ahora del otro lado.

Estados multinacionales surgidos por la fusión de varias naciones en el período considerado:

Total: 0 (cero) ${ }^{9}$.

Así pues, en la última década y media, la proporción de naciones separatistas frente a la de naciones «fusionistas» ha sido de 25/0, o sea, en términos de cálculo, infinita... Sean o no una cosa buena las «fusiones» de varias naciones en un solo Estado (según Arteta, al parecer, siguiendo a Mill, lo son), el hecho en bruto es que, al menos en los últimos tiempos, ellas brillan por su ausencia.

Ciertamente, las estadísticas son siempre aburridas. Pero a veces hay que tomarlas en cuenta, incluso si somos filósofos. Para quienes hablan de la «tendencia universal a la superación de los Estados nacionales» y cosas parecidas, una ojeada a la tabla anterior debería suscitarles por lo menos algunos quebraderos de cabeza. Claro que no quiero que se me atribuya aquí una «falacia naturalista»; ya sé que de un «ser» no se deriva sin más un «deber ser». A un antinacionalista al estilo de Arteta, la tabla anterior le dejará completamente frío: «¿Y qué con esos datos?» — dirá - «de ahí sólo se deduce que grandes porciones de la Humanidad se han vuelto locas, desgraciadamente. Estonios, letones, lituanos, eslovacos, moldavos, croatas, kurdos, tamiles, eritreos, [...] todos un hatajo de dementes y criminales. Hay que curarlos y/o reprimirlos (que es lo que hacen los rusos en Chechenia)». Desde un punto de vista estrictamente lógico, por supuesto que se puede razonar así. Sin embargo, el antinacionalista debería también tener en cuenta, en un contexto ético-político, lo que algunos teóricos del Derecho denominan «la fuerza normativa de lo fáctico», a menos que sea un adepto del famoso dictum atribuido a Hegel: «Si la realidad no se adapta a mi sistema, tanto peor para la realidad...»

Ya oigo el clamor con que algunos, quizás el propio Arteta, opondrán un aparente contraejemplo a mi deprimente estadística: ¡la Unión Europea! He aquí, me dirán, una formidable entidad política que se está constituyendo por encima de las fronteras entre naciones. Bueno, permítanseme un par de breves observaciones 
sobre la naturaleza de la Unión Europea. ¿Es un Estado multinacional? Por supuesto que no. ¿Tiene visos de convertirse pronto en un Estado de tal naturaleza? No los atisbo. ¿Hay una fuerte afinidad entre los ciudadanos de los diversos países de la Unión Europea, en el sentido de una «identidad europea» que podría ser la base para ese futuro Estado multinacional? Sostenerlo equivaldría a un mal chiste. Nadie puede pretender en serio que la afinidad cultural, nacional, o lo que sea, entre un ciudadano medio de Finlandia y uno de Portugal es mucho mayor que entre uno de Portugal y uno de Brasil. Entonces, ¿qué es la Unión Europea? A nivel económico, está claro: un club para hacer buenos negocios con menos cortapisas arancelarias y (en parte) con una moneda única. ¿Y políticamente? Xavier Rubert de Ventós ha caracterizado muy acertadamente la Unión Europea de «OPNI» («Objeto político no identificado») ${ }^{10}$. El hecho empíricamente confirmado una y otra vez es que, en las cosas que realmente importan, tanto en política interior como exterior, cada país tira por su lado. No se trata sólo de la enorme disparidad en asuntos administrativos más o menos técnicos, como la política presupuestaria, el sistema fiscal o las prioridades infraestructurales; se trata aún más de profundas divergencias en lo que podríamos calificar de tendencias políticas profundas. Si a alguien le quedaba todavía alguna duda, la fisura insuperable provocada en el seno de la Unión Europea por la cuestión de Irak le debería haber desengañado definitivamente. En resumen, no avizoro ningún Estado multinacional en ciernes ni en Europa, ni en ninguna otra parte del mundo. Y los que hemos heredado de épocas pasadas, tienen que luchar con problemas de todo tipo. Lo que veo son Estados nacionales más o menos fuertes (sobre todo uno) que imponen, o tratan de imponer, su política a los demás a base de presiones económicas y/o militares, como de costumbre. Pero ello sin duda no represen- ta el ideal de Estados democráticamente multinacionales y cada vez más amplios con los que todavía sueñan algunos cándidos «ciudadanos del mundo».

\section{Apéndice: Notas desde la lejanía sobre el País de los Conejos}

En uno de los pocos pasajes en los que Arteta se refiere explícitamente al caso que sospecho que es el único que le interesa, caracteriza el Estado español de la siguiente manera: «La España de hoy [es] un Estado multinacional» (p. 226). Éste es uno de los pocos respectos a partir del cual Arteta y yo podríamos alcanzar un amplio acuerdo. Digo «podríamos», porque hay todavía algunas cuestiones terminológicas por esclarecer, si se trata de emprender un análisis riguroso.

Estamos de acuerdo Arteta y yo en que el Estado español es un Estado multinacional. El primer problema con el que chocamos, sin embargo, es que esta caracterización no aparece en el texto de la Constitución fundamento de dicho Estado. Allí se habla de una sola nación española. En efecto, el Preámbulo de la Constitución comienza con las palabras «La Nación española...», así, en singular y con mayúscula. Y si bien en el artículo 2 aparece el vago término «nacionalidades», del cual nadie sabe exactamente a qué se refiere, en el resto del texto constitucional este vocablo no vuelve a ocurrir ni una sola vez ${ }^{11}$. De modo que, al caracterizar el Estado español como multinacional, Arteta y yo damos muestras dudosas de «patriotismo constitucional». No sé si ello le causa inquietud a Arteta. A mí no me preocupa mayormente. Para mí, una Constitución no es un libro sagrado (y si lo fuera, tanto peor para ella). Y si, en aras de la precisión y el entendimiento entre ciudadanos, hay que modificar el redactado de la Constitución, pues se hace, y basta. Olvidémonos, pues, del texto de la Consti- 
tución y quedémonos con una constatación que es, por así decir, «preconstitucional» o de orden simplemente fáctico: el Estado español es un Estado multinacional.

¿Cuáles son las naciones que administra ese Estado multinacional? Aún menos se nos aclara esto en la Constitución, aunque sería conveniente fijarlo de una vez por todas. No parece muy aventurado apostar por las siguientes naciones: los catalanes, los vascos, los gallegos y... los españoles. O sea, cuatro; ni más ni menos. Los españoles están diseminados en diversas regiones y manifiestan su españolidad de manera algo diversa según la región -andaluces, murcianos, manchegos, asturianos, etc. - . Pero todos pertenecen claramente a la misma nación: la española. Esta identidad nacional subyacente se manifiesta en gran número de fenómenos: una misma lengua, una tradición literaria muy propia desde la Edad Media, una memoria histórica marcada, entre otras cosas, por las luchas incesantes del proceso denominado usualmente «Reconquista», una música culta muy influida por el flamenco, un gusto muy divulgado por la tauromaquia, una forma particular de hacer broma y de festejar... en fin, un montón de elementos que constituyen, parafraseando a Wittgenstein, un «aire de familia» - justamente de la familia española - . Por estos elementos, puntualmente o en su conjunto, catalanes, vascos y gallegos pueden sentir respeto, interés o hasta entusiasmo; pero no son los suyos. $\mathrm{O}$ quizás, en algunos casos, los lleguen a hacer suyos (voluntariamente o coaccionados a ello); pero no son suyos en el sentido de que «les vengan dados». Por supuesto que para catalanes, vascos y gallegos podríamos dar una lista isomorfa de manifestaciones fenoménicas de sus respectivas naciones, pero los elementos de esa lista serán sustancialmente distintos.

Tenemos, pues, la nación española, además de la catalana, la vasca y la galle- ga, abarcada por el Estado español. Pero ahora empiezan los problemas terminológicos (que son algo más que eso). Es usual darle a una nación, independientemente de que disponga de un Estado propio o no, un nombre propio abstracto a partir del gentilicio con que se describe a sus miembros. Así, a la nación de los croatas se la llamó siempre «Croacia» (dispusiera o no de un Estado soberano), a la nación de los kurdos se la llama «Kurdistán», etc. A la nación de los catalanes, es natural en consecuencia llamarla «Cataluña», a la de los vascos «País Vasco» (o, preferiblemente, para evitar connotaciones puramente paisajísticas, «Euskadi»), a la de los gallegos «Galicia». ¿Cómo llamaremos a la nación de los españoles? Pues lo natural será: «España». Pero aquí nos salta el problema en las narices. Pues habíamos visto que, en la dicción de Arteta (que es también la de la inmensa mayoría de los españoles, aunque no la de la mayoría de los catalanes y los vascos, de los gallegos no sé), «España» es simplemente el nombre del Estado español. Entonces tenemos que «España» es el nombre de un Estado que administra Cataluña, Euskadi, Galicia... y España. ¿Lo entienden ustedes? Yo no. A mi juicio, la identidad «España = Estado español» es un error categorial.

La distinción entre «España» $\mathrm{y}$ «Estado español» es sin duda farragosa, pero tiene la ventaja de ser precisa y funcional. «España» es el nombre genuino de una nación. El término «Estado español», nombre de un Estado, tiene ciertamente connotaciones burocráticas. Sería mejor sustituirlo por algo que sonara mejor, al estilo de «Reino Unido» o «Confederación Helvética», otras denominaciones de Estados multinacionales. Sería bueno inventar para el Estado que aquí nos ocupa un nuevo término, más neutral; por ejemplo, «Celtiberia», «Hesperia»o, mejor aún, «País de los Conejos», como, según algunos autores, llamaban los fenicios el territorio que administra el actual Estado espa- 
ñol ${ }^{12}$. Esta denominación tendría la ventaja de ser, no sólo políticamente, sino hasta ecológicamente correcta. No obstante, como sospecho que mi propuesta terminológica no gozará de un entusiasmo universal, me quedo con el farragoso «Estado español». Ahora bien, la propuesta, ya no terminológica, sino sustancial y creo que hasta decisiva para avanzar poco a poco hacia la paz espiritual y material en el país, sería la de dejar bien claro de una vez por todas, en escuelas, academias, libros de texto, representaciones en el extranjero, monumentos, y todo género de instituciones, que «España» es el nombre de una nación (que se manifiesta principalmente por una lengua, el español), mientras que «Estado español» es el nombre de un Estado que administra a cuatro naciones $\mathrm{y}$ caracterizado entre otras cosas por el uso oficial dentro de él de cuatro lenguas. Y en las escuelas e institutos de Enseñanza Media (ya que no en las familias, no pido peras al olmo) habría que afianzar en las cabezas de los escolares destinados a ser los futuros buenos ciudadanos del Estado español una serie de principios que se desprenden de la anterior distinción entre «España»y «Estado español», siendo el más fundamental de ellos que la diversidad nacional de dicho Estado no es una terrible desgracia, sino algo de lo que cabe estar orgullosos. Sólo así lograría formarse una nueva generación de buenos ciudadanos demócratas y «republicanos» en el sentido de Arteta. ¿Una utopía? Sin duda. Pero, a mi juicio, ex utopia ista, nulla salus para el País de los Conejos.

Dado que no hay los menores atisbos de que esta utopía vaya a realizarse ni a corto ni a mediano plazo (la evolución política actual del Estado español más bien se encamina en sentido contrario), no me sorprenden las constantes broncas y tensiones en su seno. ¿Quién tiene la culpa? Para Arteta está claro: la culpa exclusiva la tienen los nacionalistas (de las naciones minoritarias). Para mí está igual- mente claro: la culpa principal la tienen los hegemonistas de la nación mayoritaria, quienes, sea cual sea el partido político por el que votan o por el que son votados, no tienen la menor intención de acercarse ni un paso a la utopía en cuestión. Y como el Estado español es efectivamente un Estado democrático en el nivel de los derechos individuales, la aplastante mayoría de la nación hegemónica siempre le ganará la partida a las minorías nacionales. Un argumentum ad quantitatem. Ante tal situación, ¿qué pueden hacer los partidarios de la utopía verdaderamente multinacional arriba descrita? Hay dos opciones. Una es resignarse en aras de la paz individual, que no nacional, y limitarse a salvar de cada nación minoritaria lo que tolere la mayoría hegemónica. La otra es tratar de construirse otro Estado que represente mejor su identidad nacional. Ambas opciones son respetables, y no seré yo quien, desde la cómoda lejanía harto mencionada, se dedique a hacerles recomendaciones en uno $\mathrm{u}$ otro sentido a los ciudadanos de las minorías nacionales del Estado español. A diferencia de Arteta y de los obispos españoles, no creo que una u otra opción sea intrínsecamente «inmoral». Lo que creo es que, ante dos opciones tan claramente delimitadas, hay un método clásico para decidir por una de ellas, un método que, siguiendo a Churchill, podemos calificar de muy malo, pero menos malo que todos los demás: preguntarles a los interesados (en este caso, las minorías nacionales del Estado español). Si 50 por $100+x$, para $x>0$, vota por la resignación, los 50 por $100-x$ restantes deberán conformarse; y por supuesto mutatis mutandis. Éste es el principio más básico de la aritmética democrática, y ningún «buen ciudadano republicano» debe admitir subterfugios ante él, ni descalificaciones morales, ni atribuciones de demencia o de estado de ebriedad, ni cosas parecidas. Sea inmoral, demente o alcoholizada, si la opción de una nación por 
constituir su propio Estado es votada por la mitad más uno de sus miembros interesados, entonces hay que aceptarla. Esto es un corolario que se desprende directamente del imperativo contenido en el inciso segundo del artículo primero de la Carta de las Naciones Unidas (suscrita por el Estado español desde hace medio siglo y tenazmente ignorada desde entonces):
Desarrollar entre las naciones relaciones amistosas fundadas en el respeto del principio de la igualdad de derechos de los pueblos y de su derecho a disponer de sí mismos.

He aquí por qué no sólo soy nacionalista, sino en caso de apuro, hasta separatista.

\section{NOTAS}

${ }^{1}$ La acusación de «deshonestidad intelectual» es particularmente grave en el contexto de un debate de ideas; ella sólo puede hacerse cuando se tienen pruebas muy sólidas. El punto respecto al cual Arteta me hace dicha acusación es de importancia muy secundaria, pero dada la gravedad de la acusación, me veo obligado a responder a ella en esta nota. La acusación se refiere a mi «uso» de John Stuart Mill. En efecto, cuando discuto diversas propuestas de definición de «nación» en mi ensayo, cito, entre otras, la presentada por Mill, según la cual una «nacionalidad» se basa en un sentimiento de simpatía mutua, y, aunque a renglón seguido la critico, admito que es un poco mejor que definiciones posteriores que se han propuesto. Arteta no puede negar que mi cita de Mill es textual y correcta. Lo que me echa en cara es que no menciono otros pasajes de Mill, en los que éste manifiesta una opinión positiva acerca del fenómeno de la «fusión» de naciones. Ahora bien, ¿por qué tenía yo que citar algo que no venía al caso en ese contexto, pues simplemente se trataba de discutir diversas caracterizaciones de lo que es una nación, no de si las «fusiones» son buenas o malas? ¿Y dónde digo yo que Mill sostenía las mismas opiniones sobre el nacionalismo que yo? Al parecer el esquema general de razonamiento que sigue Arteta es el siguiente: «El autor $A$ cita con cierta benevolencia la tesis $T$ del autor $B$. En otro pasaje, el autor $B$ sostiene otra tesis $T$ (independiente de $T$ ) supuestamente incompatible con las tesis de $A$. Luego $A$ es deshonesto.» Es cierto que hay gente de escaso nivel cultural que razonaría de esta manera. De parte de un profesor de filosofía es por lo menos inesperado...

2 Como botón de muestra de esto último, que sería divertido si no fuera penoso, está su referencia a un autor a quien yo supuestamente cito: «Juan Villoro» (p. 222). En realidad, a quien menciono varias veces en mi texto es a Luis Villoro, el filósofo, y no a su hijo Juan, el novelista. Desde estas páginas, me permito pedirle disculpas, también en nombre del Profesor Arteta, a mi amigo Juan Villoro, por verse involucrado en este berenjenal por causas ajenas a mi voluntad.
${ }^{3}$ Cabría considerar una forma más débil de negacionismo, que consistiría en aceptar la premisa puramente ontológica 1 , pero negar la de carácter más epistemológico 2: las naciones posiblemente existen, pero son entidades tan opacas que son inaccesibles a la investigación y por tanto nada sensato puede decirse acerca de ellas. En $M N$ no consideré explícitamente esta posible variante de negacionismo, pero sí me enfrenté a ella implícitamente al desarrollar mi «miniteoría de etnias y naciones», la cual es justamente un intento de justificar la premisa 2.

${ }^{4}$ Cf. C. U. Moulines, Pluralidad y recursión, cap. 2.3, Madrid, Alianza, 1991.

5 Cf. F. Requejo, «Democratic legitimacy and national pluralism», en F. Requejo (comp.), Democracy and National Pluralism, Londres, Routledge, 2001, p. 159 (mi traducción).

${ }^{6}$ Es ya un tópico señalar las tremendas «lagunas» en la memoria histórica de los españoles por lo que se refiere a su pasado reciente, en comparación con otras sociedades europeas; en el caso de Arteta, esta forma de amnesia alcanza límites insospechados.

7 «Por las buenas» significa que la secesión se llevó a cabo sin demasiadas tensiones y por mutuo acuerdo entre las partes interesadas, es decir, de manera «civilizada»; «por las semibuenas» significa que el proceso de secesión tuvo que atravesar un período de fuertes tensiones, aunque sin llegar a la violencia armada; «por las semimalas» se refiere a los casos en que las tensiones fueron muy graves, incluyendo conatos de violencia armada; «por las malas» equivale a un cruento conflicto con violencia armada generalizada.

${ }^{8}$ Dejo de lado los pequeños Estados insulares que se han constituido en los últimos años en el Pacífico, porque aquí podría argüirse que se trata de un proceso de descolonización. No voy a discutir aquí si este tipo de proceso es análogo o comparable al de la constitución de un Estado uninacional por secesión de uno previo multinacional. En aras de la argumentación, daré por descontado que descolonización y separación 
nacional son dos procesos cualitativamente distintos, $\mathrm{y}$, en lo que sigue, me restringiré al segundo tipo de proceso, el genuinamente separatista.

9 Desde 1989 ha habido sólo dos fusiones de Estados previos diferentes en un solo Estado nuevo: Alemania y Yemen. Pero justamente éstos no son casos de constitución de nuevos Estados multinacionales, sino que se trata del caso de dos Estados previos que representan la misma nación y se funden en un solo Estado uninacional.
${ }^{10}$ Cf. X. Rubert de Ventós, Catalunya: de la identitat a la independència, Barcelona, Empúries, 1999, pp. 112 ss.

11 Cf. O. Alzaga, La Constitución española de 1978 (comentario sistemático), Madrid, Ediciones del Foro, 1978, p. 102.

12 Cf. G. Bleiberg (dir.), Diccionario de Historia de España, Madrid, Revista de Occidente, 1968 (entrada «España»). 